Kristoffer T Everatt ${ }^{1^{*}}$, Leah Andresen ${ }^{1}$, William J Ripple ${ }^{2}$, and Graham IH Kerley $^{1}$

${ }^{1}$ Centre for African Conservation

Ecology, Department of Zoology,

Nelson Mandela Metropolitan

University, Port Elizabeth, South

Africa*(kteveratt@gmail.com);

${ }^{2}$ Global Trophic Cascades Program,

Department of Forest Ecosystems and

Society, Oregon State University,

Corvallis, $\mathrm{OR}$

Becker M, McRobb R, Watson F, et al. 2013. Evaluating wire-snare poaching trends and the impacts of by-catch on elephants and large carnivores. Biol Conserv 158: 26-36.

Carbone C and Gittleman JL. 2002. A common rule for the scaling of carnivore density. Science 295: 2273-76.

Clements HS, Tambling CJ, Hayward MW, and Kerley GIH. 2014. An objective approach to determining the weight ranges of prey preferred by and accessible to the five large African carnivores. PLoS ONE 9: e101054.

Creel S and Creel NM. 1996. Limitation of African wild dogs by competition with larger carnivores. Conserv Biol 10: 526-38.

Cromsigt JPGM and te Beest $M$. 2014. Restoration of a megaherbivore: landscape-level impacts of white rhinoceros in Kruger National Park, South Africa. J Ecol; doi:10.1111/136 5-2745.12218.

Durant SM. 1998. Competition refuges and coexistence: an example from Serengeti carnivores. J Anim Ecol 67: 370-86.

Els H. 2002. The role of African rural people in their environment. In: Bothma J du $\mathrm{P}$ (Ed). Game ranch management (4th edn). Pretoria, South Africa: Van Schaik Publishers.

Estes RD. 1992. The behaviour guide to African mammals. Berkeley, CA: University of California Press.

Estes JA, Terborgh J, Brashares JS, et al. 2011. Trophic downgrading of Planet Earth. Science 333: 301-06.

Everatt KT. 2015. Improving the conservation prospects for lions in the Greater Limpopo Lion Conservation Unit; determining key threats and identifying appropriate solutions. http://bit.ly/1TrEIpo. Viewed 1 Dec 2015.

Everatt KT, Andresen L, and Somers MJ. 2014. Trophic scaling and occupancy analysis reveals a lion population held below carrying capacity by top-down anthropogenic pressure in the Limpopo National Park, Mozambique. PLoS ONE 9: e99389.
McLoughlin CA and Owen-Smith N. 2003. Viability of a diminishing roan antelope population: predation is the threat. Anim Conserv 6: 231-36.

Oosthuizen S. 2014. Meet the poachers. SANPark Times 06.

Owen-Smith N. 1988. Megaherbivores: the influence of very large body size on ecology. Cambridge, UK: Cambridge University Press.

Packer C, Hilborn R, Mosser A, et al. 2005. Ecological change, group territoriality, and population dynamics in Serengeti lions. Science 307: 390-93.

Ripple WJ, Wirsing AJ, Wilmers CC, and Letnic M. 2013. Widespread mesopredator effects after wolf extirpation. Biol Conserv 160: 70-79.

Ripple WJ, Estes JA, Beschta RL, et al. 2014. Status and ecological effects of the world's largest carnivores. Science 343; doi:10.1126/science.1241484.

Ripple WJ, Newsome TM, Wolf C, et al. 2015. Collapse of the world's largest herbivores. Science Advances 1: e1400103.

van der Meer E, Rasmussen GSA, and Fritz H. 2014. Using an energetic cost-benefit approach to identify ecological traps: the case of the African wild dog. Anim Conserv 18: 359-66.

White PA and Diedrich CG. 2012. Taphonomy story of a modern African elephant Loxodonta africana carcass on a lakeshore in Zambia (Africa). Quatern Int 267: 287-96.

doi $: 10.1002 /$ fee. 1202

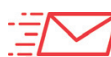

\section{The moral basis for conservation - reflections on Dickman et al.}

Dickman et al. (2015; Front Ecol Environ 13[6]: 325-31) suggested that "moral relativism" and "misguided respect" for cultural practices impede biological conservation. They favor a world in which conservation scientists armed with universal norms will more readily implement their solutions without the consent of local stakeholders. While we acknowledge their concerns, their vision, however tentative, appears misguided. Here we highlight some objections.

The authors suggest their interventions are justified by universal values and scientific rationality. But society also protects cultural diversity and human rights on the basis of philosophy and universal values (Maffi 2005; Elliott 2014). Sen, whose non-relativist views were mentioned, actually proposed universal human capacities and freedoms that he wanted to see protected, not undermined, though he acknowledged these principles do not readily yield a practical means to make choices by calculation (Sen 1988). Human rights related to conservation actions enjoy widespread, often legal, recognition (Elliott 2014) and have motivated various international agreements (eg www.unccd.int, http://undesadspd.org, www.cbd. int, and www.ilo.org). "Free, prior, and informed consent" is a principle emphasized in these agreements and others (Hanna and Vanclay 2013).

Dickman et al. fail to recognize that conservation serves a plurality of people and principles. Furthermore, conservation represents one set of societal goals among many; choices are necessary to allocate resources and manage trade-offs. The challenge is how to reconcile competing values and human rights.

We propose that the route to legitimacy lies in respecting democratic and legal principles. Such principles acknowledge different views and perspectives. Scientists should draw on their knowledge to inform choices, but scientific utility is no excuse for tyranny by scientists (Sheil and Meijaard 2010). The ends and means of science represent one subset of the ends and means of society as a whole.

Relativism takes many forms. In conservation, "relativism" emphasizes inclusive and respectful approaches. This is a guiding principle, not a fundamental doctrine. Such relativism reflects the diversity of perspectives that occur even within science.

Scientific views are seldom monolithic. Applied science is often controversial, even among scientists, and normative assessments differ (Vedeld 1994). Perceptions, framing, and preferred outcomes vary among stakeholders, including sci- 


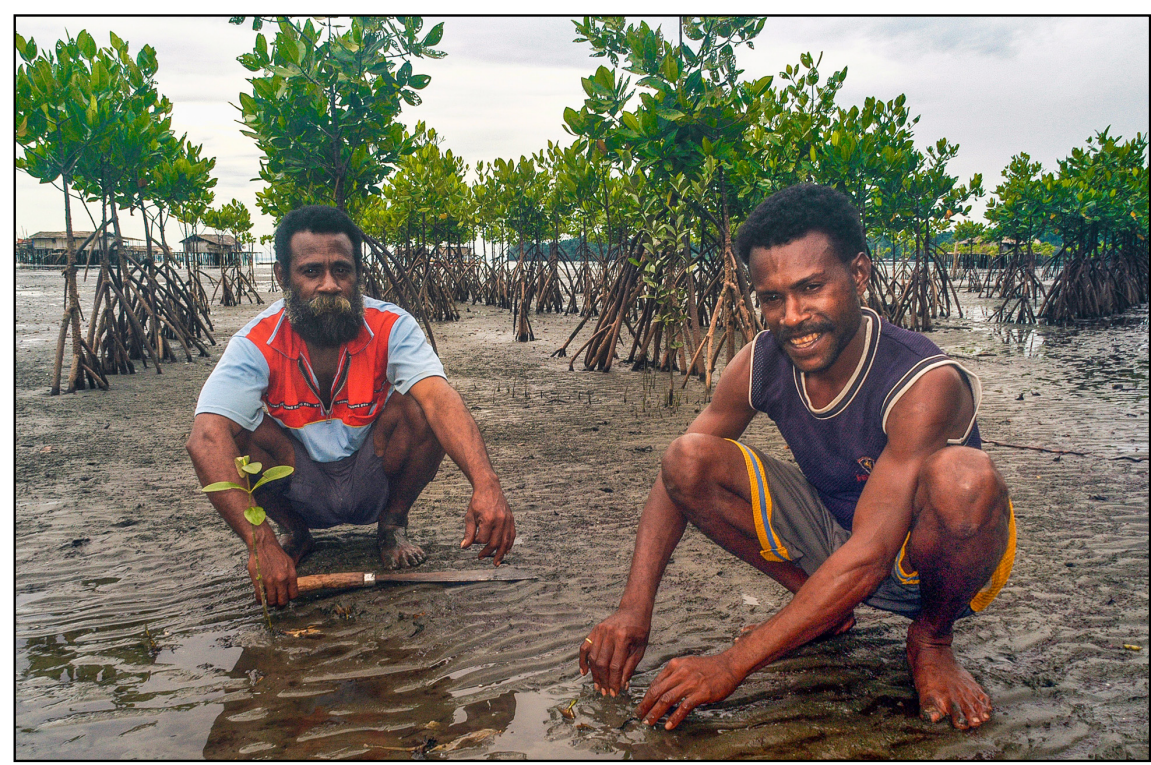

Figure 1. Community-based mangrove restoration initiated by faith-based NGOs and implemented by local church members in Warironi village, Yapen Island, Papua, Indonesia.

entists (Newell et al. 2014). Dubious claims of objectivity and unanimity undermine conservation scientists' credibility and effectiveness (Sheil and Meijaard 2010). Many of us already face accusations of double standards, given our apparent inability to maintain objectivity when observing the threats to biodiversity due to our own cultures (Meijaard and Sheil 2011).

The authors note that "the objective of conservationists is not the imposition of Western values, but the development of a policy that is consistent with the relevant conservation goals". But preferences for pandas and penguins over bats and bivalves are not based on science.

Dickman et al. suggest illustrations of relativism impeding conservation but offer no evidence. The benefits of maintaining good relations with local people and accessing local knowledge to implement any solution seem adequate reason to avoid a rush to confrontation. The cases underline how engagement and the collaborative re-workings of cultural norms substituting fake fur capes for animal hides - can benefit outcomes.

At least one-half of the land placed under official protection dur- ing the past century was previously used by people (Dowie 2011). Such interventions, typically performed without local consent, complicate conservation initiatives by causing alienation, distrust, and conflict (Dowie 2011; Sheil et al. 2015). We should condemn such practices, not endorse them.

The authors decry the "moral opportunism" of working with cultural beliefs to achieve conservation because this somehow contaminates their discipline's scientific foundations. These views are perplexing. Around 85\% of the world's population embrace a religious faith. Their beliefs and associated practices influence their lives and often affect conservation goals (Hitzhusen and Tucker 2013). Dickman et al. neglect to discuss how environmental groups and faith-based organizations are finding common purpose worldwide, though this appears among the most constructive developments in contemporary times (eg www.arcworld.org/ arc_and_the_faiths.asp) (Figure $1)$. Science remains uncompromised when scientists acknowledge the role of values and non-scientific considerations in their work and remain honest and humble about their science and its uncertainties.

The authors' appeals are reminiscent of the "enlightened absolutism" guiding tropical conservation in the colonial era. Such approaches are obsolete. Inclusive conservation practices are increasingly grounded in scientific assessments of effectiveness (Porter-Bolland et al. 2012; Stevens et al. 2014). Scientists alone cannot maintain a healthy planet we need help, not conflict. Certainly, we should work to modify unsustainable practices, but respect is a precondition for cooperation. As Dickman et al. concede, other cultures are often sympathetic to conservation goals. This highlights potential common ground. Sustainability favors both cultures and conservation.

We applaud principles that invite us to "respect and incorporate different worldviews and knowledge systems into conservation planning" (Gavin et al. 2015). Achieving sustainable outcomes requires balancing and negotiating - as opposed to dominating - worldviews. Such engagement rewards patience and humility. For all of the aforementioned reasons, concerns over relativism and "misguided respect" themselves appear misguided.

Douglas Sheil ${ }^{1^{*}}$, Jane Cohen ${ }^{2}$, Carol J Pierce Colfer ${ }^{3,4}$, David Price, Rajindra Puri ${ }^{6}$, Manuel Ruiz-Perez ${ }^{7}$, Yulia Sugandi ${ }^{8}$, Paul Vedeld ${ }^{9}$, Eva Wollenberg $^{10}$, and Yurdi Yasmi ${ }^{11}$

${ }^{1}$ Department of Ecology and Natural Resource Management, Norwegian University of Life Sciences, As, Norway*(douglas.sheil@nmbu.no); ${ }^{2}$ Faculty of Law, The University of Texas at Austin, Austin, TX;

${ }^{3}$ Southeast Asia Program, Cornell University, Ithaca, NY; ${ }^{4}$ Center for International Forestry Research, Bogor, Indonesia; ${ }^{5}$ Massey University, Palmerston North, New Zealand; ${ }^{6}$ Centre for Biocultural Diversity, 
School of Anthropology and

Conservation, University of Kent at Canterbury, Kent, UK; ${ }^{7}$ Department of Ecology, Faculty of Sciences, Autonomous University of Madrid, Madrid, Spain; ${ }^{8}$ Department of

Community Development and

Communication Sciences, Faculty of

Human Ecology, Bogor Agricultural

University, Bogor, Indonesia;

${ }^{9}$ NORAGRIC, Norwegian University

of Life Sciences, Ås, Norway;

${ }^{10}$ CGIAR Research Program on

Climate Change, Agriculture and Food

Security (CCAFS), Gund Institute,

University of Vermont, Burlington,

VT; ${ }^{11}$ FAO Regional Office for Asia

and the Pacific, Bangkok, Thailand

Dowie M. 2011. Conservation refugees: the hundred-year conflict between global conservation and native peoples. Cambridge, MA, and London, UK: MIT Press.

Elliott MA. 2014. The institutionalization of human rights and its discontents: a world cultural perspective. Cult Sociol 8: 407-25; doi:10.1177/1749975514541099.

Gavin MC, McCarter J, Mead A, et al. 2015. Defining biocultural approaches to conservation. Trends Ecol Evol 30: $140-45$.

Hanna P and Vanclay F. 2013. Human rights, indigenous peoples and the concept of free, prior and informed consent. Impact Assess Proj Appr 31: 146-57.

Hitzhusen GE and Tucker ME. 2013. The potential of religion for Earth stewardship. Front Ecol Environ 11: 368-76.

Maffi L. 2005. Linguistic, cultural, and biological diversity. Annu Rev Anthropol 34: 599-617.

Meijaard E and Sheil D. 2011. A modest proposal for wealthy countries to reforest their land for the common good. Biotropica 43: 524-28.

Newell BR, McDonald RI, Brewer M, and Hayes BK. 2014. The psychology of environmental decisions. Annu Rev Environ Resour 39: 443-67.

Porter-Bolland L, Ellis EA, Guariguata MR, et al. 2012. Community managed forests and forest protected areas: an assessment of their conservation effectiveness across the tropics. Forest Ecol Manage 268: 6-17.

Sen A. 1988. The concept of development. In: Chenery $\mathrm{H}$ and Srinivasan $\mathrm{TN}$ (Eds). Handbook of development economics. North Holland, Amsterdam: Elsevier Science Publishers BV.
Sheil D, Boissière $M$, and Beaudoin G. 2015. Unseen sentinels: local monitoring and control in conservation's blind spots. Ecol Soc 20: 39.

Sheil D and Meijaard E. 2010. Purity and prejudice: deluding ourselves about biodiversity conservation. Biotropica 42: 566-68.

Stevens C, Winterbottom R, Springer J, and Reytar K. 2014. Securing rights, combating climate change: how strengthening community forest rights mitigates climate change. Washington, DC: World Resources Institute.

Vedeld PO. 1994. The environment and interdisciplinarity ecological and neoclassical economical approaches to the use of natural resources. Ecol Econ 10: 1-13.

doi: $10.1002 /$ fee. 1224

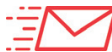

\section{The authors' reply}

While conservation science is an evidence-based endeavor, ethical considerations are important for formulating conservation policy. We believe that the influence of cultural relativism on ethics has been somewhat neglected by conservationists. That was the motivation for our piece (2015; Front Ecol Environ 13[6]: 325-31). We are delighted to see the interest it has sparked in the letter by Sheil et al. However, Sheil et al. have misunderstood us in places, which we seek to clarify here.

We cannot see how our piece can be interpreted as advocating conservation action "without the consent of local stakeholders". We emphasized that heavy-handed approaches to conservation have often failed, at least partly because they were perceived as echoing Western imperialism. In our paper's second WebPanel, we gave examples of poor conservation outcomes following the forced removal of people and cattle from parks. Even where conservation goals are achieved, we do not support "tyranny" by scientists. We entirely agree with Sheil et al. that "We should condemn such practices, not endorse them". Sheil et al. note that the "enlightened absolutism" driving conservation in the colonial era is "obsolete". It is a mystery to us how our paper could be interpreted as supporting that indubitably obsolete view. Indeed, we held up the example of the Kenyan "Lion Guardians" program as a model of good practice. A cultural practice was recognized as a conservation issue, and transformation was achieved by persuasion and cooperation, not coercion. This was also true of the Panthera campaign to substitute fake fur for leopard skins in Shembe ceremonies. We gave these as examples of exactly the benefits of "collaborative reworkings of social norms" to which Sheil et al. refer. A "rush to confrontation" is, we agree, likely to exacerbate human-wildlife conflict.

Our central argument was that elements of different cultural practices that negatively affect conservation may be respected for no other reason than that they constitute part of a culture, and that perception may inhibit action. Our case histories show where that idea may be influential. In an earlier correspondence with Sheil, we were alerted to a study concerning the conservation of hornbills (Buceros spp) in Borneo, as an example of sensitive engagement of conservationists with local culture (Bennett et al. 1997). The recommendations emerging from that study summarize our case even better than our original examples. The hornbills were hunted unsustainably for both meat and ornamentation for ceremonial costumes. The first two concluding recommendations of the paper are: (1) hunting for meat alone should be stopped and (2) hunting for feathers should be reduced to levels that are sustainable. Why the difference? Pragmatic considerations may be responsible. It is true that we cannot prove that relativism is at work in any of our case histories - the mindsets of the conservation agents are not accessible to us. But we suspect it is, and it is overstating the case to say we "offer no evidence".

Sheil et al. appear to have confused our message concerning the influence of relativism in inhibit- 